\title{
The incidence of geriatric trauma is increasing and comparison of different scoring tools for the prediction of in- hospital mortality in geriatric trauma patients
}

\author{
Libing Jiang, Zhongjun Zheng and Mao Zhang*
}

\begin{abstract}
Purpose: The study aimed to examine the changing incidence of geriatric trauma and evaluate the predictive ability of different scoring tools for in-hospital mortality in geriatric trauma patients.

Methods: Annual reports released by the National Trauma Database (NTDB) in the USA from 2005 to 2015 and the Trauma Register DGU ${ }^{\otimes}$ in Germany from 1994 to 2012 were analyzed to examine the changing incidence of geriatric trauma. Secondary analysis of a single-center cohort study conducted among 311 severely injured geriatric trauma patients in a level I trauma center in Switzerland was completed. According to the in-hospital survival status, patients were divided into the survival and non-survival group. The differences of the ISS (injury severity score), NISS (new injury severity score), TRISS (Trauma and Injury Severity Score), APACHE II (Acute Physiology and Chronic Health Evaluation II), and SPAS II (simplified acute physiology score II) between two groups were evaluated. Then, the areas under the receiver-operating characteristic curve (AUC-ROC) of different scoring tools for the prediction of in-hospital mortality in geriatric trauma patients were calculated.
\end{abstract}

Results: The analysis of the NTDB showed that the increase in the number of geriatric trauma ranged from 18 to $30 \%$ between 2005 and 2015. The analysis of the $\mathrm{DGU}^{\circledR}$ showed that the mean age of trauma patients rose from 39.11 in 1993 to 51.10 in 2013, and the proportion of patients aged $\geq 60$ years rose from 16.5 to 37.5\%. The findings from the secondary analysis showed that 164 (52.73\%) patients died in the hospital. The ISS, NISS, APACHE II, and SAPS II in the death group were significantly higher than those in the survival group, and the TRISS in the death group was significantly lower than those in the survival group. The AUCS of the ISS, NISS, TRISS, APACHE II, and SAPS II for the prediction of in-hospital mortality in geriatric trauma patients were $0.807,0.850,0.828,0.715$, and 0.725 , respectively.

Conclusion: The total number of geriatric trauma is increasing as the population ages. The accuracy of ISS, NISS and TRISS was higher than the APACHE II and SAPS II for the prediction of in-hospital mortality in geriatric trauma patients.

Keywords: Elderly trauma, Geriatric trauma, Aging population, In-hospital mortality, Scoring tool

\footnotetext{
* Correspondence: z2jzk@zju.edu.cn

Department of Emergency Medicine, The Second Affiliated Hospital, Zhejiang

University School of Medicine, Jiefang road 88, Hangzhou, China
}

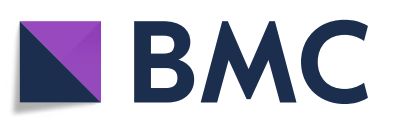

( ) The Author(s). 2020 Open Access This article is licensed under a Creative Commons Attribution 4.0 International License, which permits use, sharing, adaptation, distribution and reproduction in any medium or format, as long as you give appropriate credit to the original author(s) and the source, provide a link to the Creative Commons licence, and indicate if changes were made. The images or other third party material in this article are included in the article's Creative Commons licence, unless indicated otherwise in a credit line to the material. If material is not included in the article's Creative Commons licence and your intended use is not permitted by statutory regulation or exceeds the permitted use, you will need to obtain permission directly from the copyright holder. To view a copy of this licence, visit http://creativecommons.org/licenses/by/4.0/ The Creative Commons Public Domain Dedication waiver (http://creativecommons.org/publicdomain/zero/1.0/) applies to the data made available in this article, unless otherwise stated in a credit line to the data. 


\section{Background}

Trauma is the fourth leading cause of death overall for all ages and the leading cause of death among young people aged less than 45 years [1]. Introduction of advanced trauma care system has significantly improved the outcome of trauma patients [2]. However, along with the aging population, geriatric trauma is rapidly becoming a major public health concern [3]. Geriatric trauma patients are more prone to poor prognosis due to complicated underlying diseases, various medication use, and limited physiological reserve [4-8]. A growing number of countries have pay attention to these populations, and some researchers even suggested it is necessary to build specific geriatric trauma centers [9-11]. However, there is lack of convincing evidence that the incidence of geriatric trauma is increasing. Additionally, accurate prognosis assessment is important for clinical decision-making in geriatric trauma patients [12-14]. A number of injury severity measures are developed for the purpose of outcome prediction [15], but few are validated in the geriatric trauma population. The study aimed to examine the changing incidence of geriatric trauma and evaluate the predictive ability of the ISS (injury severity score), NISS (new injury severity score), TRISS (Trauma and Injury Severity Score), APACHE II (Acute Physiology and Chronic Health Evaluation II) and SAPS II (simplified acute physiology score II) for the prediction of in-hospital mortality in geriatric trauma patients.

\section{Methods}

The annual reports of the National Trauma Database (NTDB) in the USA from 2005 to 2015 (https://www.facs. org/quality-programs/trauma/tqp/center-programs/ntdb/ docpub) and the Trauma Register DGU ${ }^{\circ}$ in Germany from 1994 to 2012 (http://www.traumaregister-dgu.de/) were searched to examine the changing incidence of geriatric trauma. Through analysis of the NTDB, the proportion of geriatric trauma and corresponding death rates in the USA were calculated. Based on the data in the DGU ${ }^{\oplus}$ obtained by contacting the Prof. Dr. Rolf Lefering (Institut für Forschung in der Operativen Medizin; Fakultät für Gesundheit der Universität Witten/Herdecke), we calculated the mean age of trauma patients and the proportion of trauma patients aged $\geq 60$ years and their trends over time. There is a lack of specific trauma database in China. Thus, we searched the annual reports of the National Bureau of Statistics of the People's Republic of China (http:// www.stats.gov.cn/), and the proportion of population aged $\geq 65$ was calculated.

Secondary analysis of a single-center cohort study conducted among 311 severely injured geriatric trauma patients in a level I trauma center in Switzerland was completed [16, 17]. The authors in their original article evaluated the effects of standards of practice (SOP) on geriatric trauma patients $[16,17]$. Categorical variables were represented as numbers and percentages, and continuous variables were represented as median (inter-quartile range). According to the in-hospital survival status, patients were divided into the survival and non-survival group. The differences of the ISS, NISS, TRISS, APACHE II, and SPAS II (Additional file 1 provides more details about these scoring tools) between two groups were evaluated. Then, the areas under the receiver-operating characteristic curve (AUC-ROC) of different scoring tools for the prediction of in-hospital mortality in geriatric trauma patients were calculated. Differences between groups at baseline were analyzed with the use of corresponding tests (twosample $t$ test or Mann-Whitney $U$ test were used for continuous variables and chi-square test or Fisher's exact test were used for categorical variables). All statistical process was performed using IBM SPSS 20.0 (Zhejiang University) and $P<0.05$ was regarded as statistical significance.

\section{Results}

\section{The incidence of geriatric trauma is increasing}

The analysis of the NTDB showed that the increase in the number of geriatric trauma ranged from 18 to $30 \%$ between 2005 and 2015. Meanwhile, the proportion of trauma patients aged less than 65 years declined during the same period (Fig. 1a). The death rate of geriatric trauma patients was significantly higher than that of their younger counterparts. Additionally, the results showed that men had a significantly higher mortality rate than women in geriatric trauma patients (Fig. 1b). Eighty nine thousand patients with ISS (injury severity score) $\geq 9$ in the $\mathrm{DGU}^{\circ}$ was analyzed. The mean age rose from 39.11 years in 1993 to 51.10 years in 2013, and the proportion of those aged $\geq 60$ years rose from 16.5 to 37.5\% between 1993 and 2013 (Fig. 1c, d). In China, major trauma accounts for more than 60 million visits annually to hospitals, and is responsible for 700,000 to 800,000 deaths per year [18]. Based on the statistics of $\mathrm{Na}$ tional Bureau of Statistics of the People's Republic of China (http://www.stats.gov.cn/), the proportion of the population who aged 65 or above increased from $7.7 \%$ to $10.1 \%$ between 2005 and 2014 (Fig. 1e).

\section{Comparison of different scoring tools for the prediction of in-hospital mortality in geriatric trauma patients}

The sample included 311 patients aged $\geq 65$ years $[16,17]$, while $59.00 \%$ were male. One hundred and sixty-four (52.73\%) patients died in the hospital. Table 1 shows the detailed characteristics of included patients. There was no significant difference between the survival and death group, in terms of trauma mechanism, base excess, body mass index, leucocytes, thrombocytes, prothrombin, systolic blood pressure, mean artery pressure, and temperature. Patients in the death group were older than those in the survival group. The survivors of geriatric trauma had higher GCS (Glasgow coma Scale) and hemoglobin level, and lower lactate level than the patients 


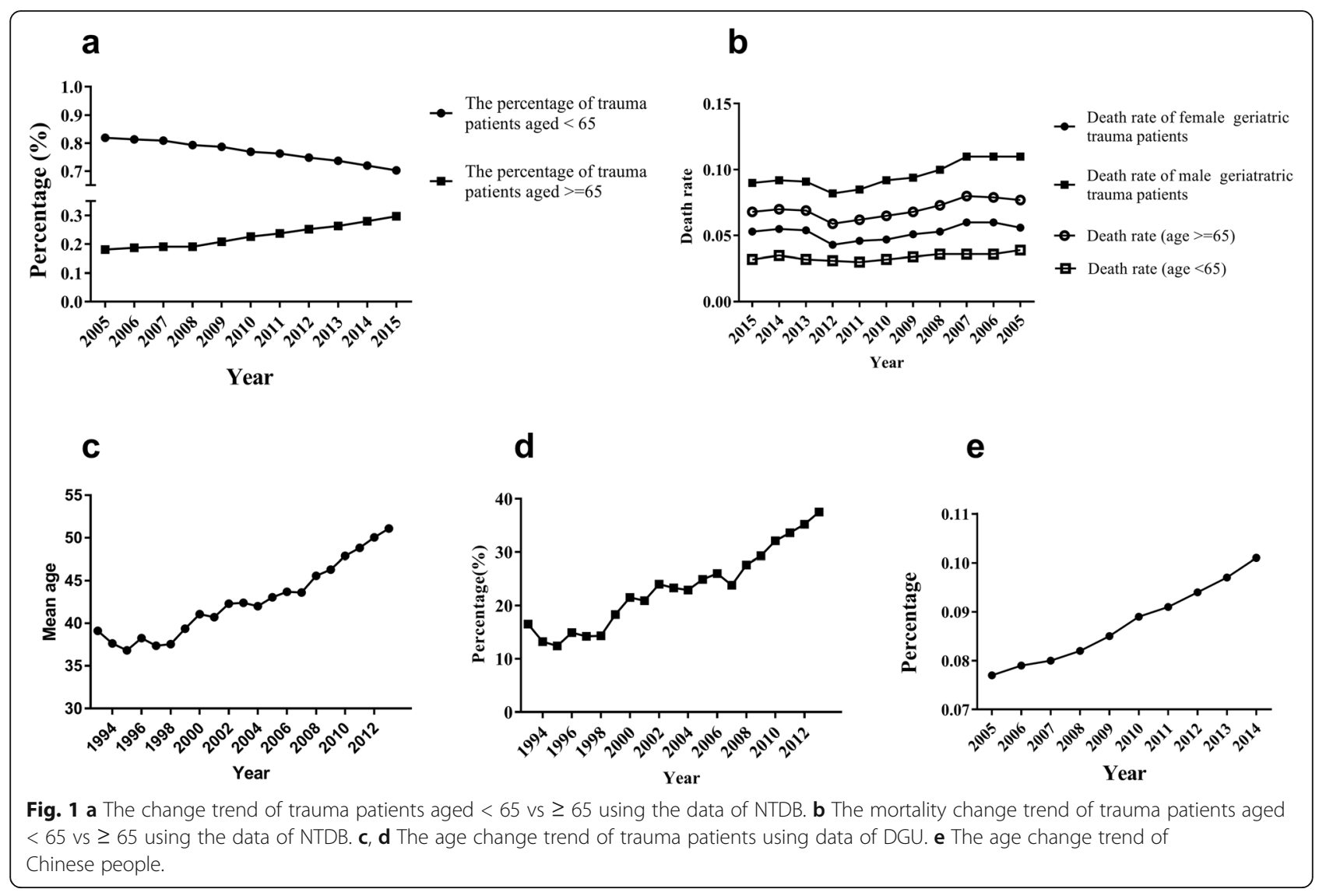

who died. We found the length of ICU stay and length of hospital stay were significantly shorter in the death group compared to the survival group.

The ISS $(34.00$ vs $24.00, P<0.01)$, NISS $(50.00$ vs $27.00, P<0.01)$, APACHE II (23.00 vs $15.00, P<0.01)$, and SAPS II $(55.00$ vs $34.00, P<0.01)$ in the death group were significantly higher than that in the survival group. The median TRISS was significantly lower in the death group than that in the survival group $(0.51$ vs $0.96, P<$ 0.01) (Table 2 and Fig. 2).

The AUCs were calculated to assess the performance of different scoring tools for the prediction of in-hospital mortality in geriatric trauma patients. Table 3 and Fig. 3 shows the AUC of the ISS was 0.807 , NISS was 0.850 , TRISS was 0.828 , APACHE II was 0.715 , and SPAS II was 0.725 . Table 4 shows the difference between the AUCs of different scoring tools. Compared with APACHE II and SAPS II, the ISS, NISS, and TRISS appear to be better predictors of inhospital mortality in elderly trauma patients. Especially the AUCs of NISS and TRISS were significantly higher than that of the APACHE II and SPAS II $(P<0.01)$.

\section{Discussion}

With the increasingly aging of the population, the incidence of geriatric trauma tends to increase. The study aimed to examine the changing incidence of geriatric trauma and evaluate the predictive ability of different scoring tools for the prediction of in-hospital mortality in geriatric trauma patients. Firstly, through analysis of the annual reports of two large trauma databases, we found the mean age of trauma patients and the proportion of geriatric trauma patients are increasing. Then, secondary analysis of a cohort study showed that the ISS, NISS, and TRISS were better than the SAPS II and APACHE II for the prediction of in-hospital mortality in geriatric trauma patients.

Increased life expectancy and independent and active lifestyle expose a great number of elderly people to serious accidents $[19,20]$. Additionally, the elderly may be more susceptible to injury due to multiple comorbidities and physical changes associated with aging (decreased vision, hearing loss, and some level of neurocognitive decline etc.). Kehoe et al. in their study also found the mean age of major trauma patients had increased from 36.1 years in 1990 to 53.8 years in 2013 [21]. It is predicted that nearly $40 \%$ of all injured patients are expected to exceed age 65 years by 2050 [22]. However, this prediction had been exceeded at Lehigh Valley Health Network in 2013 [23]. Bortz el al reported in their study that $46.6 \%$ of all trauma patients aged 65 or 
Table 1 Characteristics of included patients

\begin{tabular}{|c|c|c|c|}
\hline & Survival & Death & $P$ value \\
\hline Number of patient & 147 & 164 & \\
\hline \multicolumn{4}{|l|}{ Trauma mechanism } \\
\hline Blunt & $144(48.30 \%)$ & 154(51.70\%) & \multirow[t]{2}{*}{0.07} \\
\hline Penetrating & $3(23.10 \%)$ & $10(76.90 \%)$ & \\
\hline \multicolumn{4}{|l|}{ GCS } \\
\hline $3-8$ & $47(27.30 \%)$ & $125(72.7-\%)$ & \multirow[t]{3}{*}{$<0.01$} \\
\hline $9-12$ & $22(61.10 \%)$ & 14(38.90\%) & \\
\hline $13-15$ & $78(75.70 \%)$ & $25(24.30 \%)$ & \\
\hline Age & 74.00 (68.25 to 80.00$)$ & $78.00(72.00$ to 83.00$)$ & $<0.01$ \\
\hline Base excess $[\mathrm{mEq} / \mathrm{L}]$ & $-2.80(-5.50$ to -0.80$)$ & $-3.25(-7.80$ to -0.55$)$ & 0.32 \\
\hline Body mass index & 25.95 (22.89 to 28.40$)$ & 25.90(22.04 to 29.16) & 0.74 \\
\hline Hemoglobin $[\mathrm{g} / \mathrm{L}]$ & $11.80(9.90$ to 13.10$)$ & $10.60(8.10$ to 12.20$)$ & $<0.01$ \\
\hline Lactate $[\mathrm{mmol} / \mathrm{L}]$ & $1.90(1.15$ to 2.80$)$ & $2.10(1.40$ to 3.40$)$ & 0.03 \\
\hline Los of hospital [days] & 16.50 (9.00 to 25.00$)$ & $1.50(1.00$ to 3.00$)$ & $<0.01$ \\
\hline Leucocytes $[10 \wedge 9 / L]$ & $10.49(7.33$ to 13.96$)$ & $11.12(6.96$ to 14.24$)$ & 0.86 \\
\hline Thrombocytes [10^9/L] & $190.50(152.00$ to 239.50$)$ & $174.00(132.00$ to 230.00$)$ & 0.07 \\
\hline Prothrombin [\% normal] & 80.00 (59.00 to 95.00$)$ & $74.00(52.00$ to 89.25$)$ & 0.08 \\
\hline Systolic pressure mmHg] & 142.50 (115.00 to 160.000$)$ & $125.00(110.00$ to 158.75$)$ & 0.09 \\
\hline Mean artery pressure $[\mathrm{mmHg}]$ & 100.00 (82.00 to 112.75$)$ & $92.00(76.50$ to 113.50$)$ & 0.22 \\
\hline Temperature & $35.40(34.50$ to 36.20$)$ & $35.25(34.10$ to 36.00$)$ & 0.31 \\
\hline Los of ICU [days] & 5.00 (2.00 to 12.00$)$ & $1.00(0.50$ to 2.00$)$ & $<0.01$ \\
\hline Los of MV [days] & $1.00(0.00$ to 6.25$)$ & $1.00(0.25$ to 2.00$)$ & 0.04 \\
\hline
\end{tabular}

GCS Glasgow score, Los length of stay, ICU intensive care unit, $M V$ mechanical ventilation

greater, and $17.7 \%$ aged 85 or greater [23]. Christopher et al. evaluated the effects of a new system on mortality in trauma patients in England, and they found the median age of the patients increased from 45 to 59 years between 2008 and 2017. Additionally, they found the proportion of major trauma patients aged 65 years or more increased from 22 to $42 \%$ during the study period [24]. Beck et al. described temporal trends in the incidence of major trauma in older adults, and they found that the proportion of patients with major trauma who were aged 65 years or more increased from 25.1 to

Table 2 Comparison of different scoring tools between two groups

\begin{tabular}{llll}
\hline & Survival & Death & $P$ value \\
\hline ISS & $24.00(14.50$ to 29.00$)$ & $34.00(25.00$ to 75.00$)$ & $<0.01$ \\
NISS & $27.00(22.00$ to 38.00$)$ & $50.00(34.00$ to 75.00$)$ & $<0.01$ \\
TRISS & $0.96(0.78$ to 0.99$)$ & $0.51(0.11$ to 0.82$)$ & $<0.01$ \\
APACHE II & $15.00(10.00$ to 22.00$)$ & $23.00(19.00$ to 29.00$)$ & $<0.01$ \\
SPAS II & $34.00(27.00$ to 55.00$)$ & $55.00(34.75$ to 61.00$)$ & $<0.01$
\end{tabular}

SPAS // simplified acute physiology score II, APACHE // Acute Physiology and Chronic Health Evaluation II, ISS injury severity score, NISS new injury severity score, TRISS Trauma and Injury Severity Score
$36.7 \%$ between 2007 and 2016 [25]. The incidence of geriatric trauma increased by $4.3 \%$ per year [25].

Accurate prognostic expectations are important for decision-making in geriatric trauma patients. Several scoring systems have been developed in an attempt to accurately predict outcomes for trauma patients [13]. The ISS is a widely recognized anatomical scoring system to assess injury severity, which is equal to the squared values of the three most severely injured body areas [26]. However, the ISS ignores the serious injuries that occurring in the same anatomical area. The NISS has been reported to be better than the ISS in measuring the severity of multiple trauma patients, which considers the three most serious injuries, regardless of body region [27-29]. The TRISS is the most commonly used score for benchmarking trauma fatality outcome, based on age, revised trauma score (RTS), and the ISS [30]. However, the RTS is difficult to be obtained in sedated/intubated patients. Most studies showed that the NISS and TRISS were better than the ISS for the prediction of outcome in trauma patients [31]. Yousefzadeh-Chabok et al. reported the AUCs of the ISS and TRISS in predicting mortality among geriatric trauma patients were 0.76 and 0.94 [32]. Homanna Javali et al. also compared the ISS, 

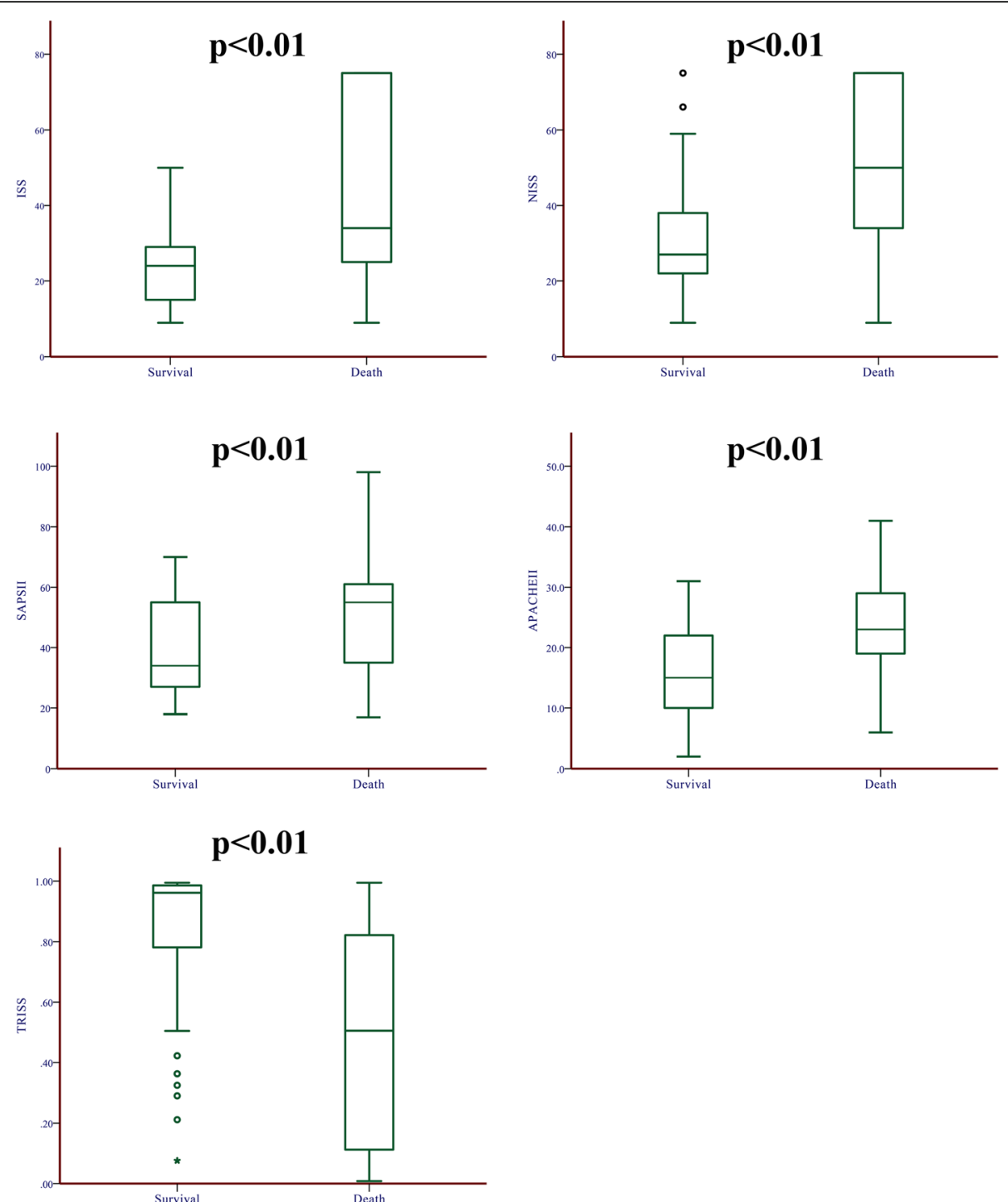

Fig. 2 The comparison of ISS, NISS, APACHE II, SPAS II, and TRISS between the survival group and death group. ISS, injury severity score; NISS, new injury severity score; SPAS II, simplified acute physiology score II; APACHE II, Acute Physiology and Chronic Health Evaluation II; TRISS, Trauma and Injury Severity Score

Table 3 Diagnostic value of different scoring tool in predicting in-hospital mortality

\begin{tabular}{lll}
\hline & AUC & $\mathbf{9 5 \%}$ Cl of AUC \\
\hline APACHE II & 0.715 & 0.644 to 0.778 \\
ISS & 0.807 & 0.743 to 0.861 \\
NISS & 0.850 & 0.790 to 0.898 \\
SPAS II & 0.725 & 0.655 to 0.788 \\
TRISS & 0.828 & 0.766 to 0.880 \\
\hline
\end{tabular}

SPAS // simplified acute physiology score II, APACHE // Acute Physiology and Chronic Health Evaluation II, ISS injury severity score, NISS new injury severity score, TRISS Trauma and Injury Severity Score, AUC area under the receiver operating characteristic curve
NISS, and TRISS for predicting mortality in cases of geriatric trauma, and the corresponding AUCs were $0.963,0.970$, and 0.972 , respectively [31].

The APACHE II and SAPS II are generally used to measure the severity and predict outcome for critically ill patients. There was no significant difference between the APACHE II versus the TRISS for the prediction of mortality in severe trauma patients [33-36]. The results of the study by Reiter et al. showed the AUCs of the SAPS II and TRISS in predicting mortality in severe trauma patients were 0.87 and 0.84 [37]. Philipp et al. reported the AUCs of the TRISS and SAPS II for the prediction mortality in multiple-trauma patients was 0.83 and 0.86 [38]. Both studies found the combination of different scores might improve the predictive ability. 

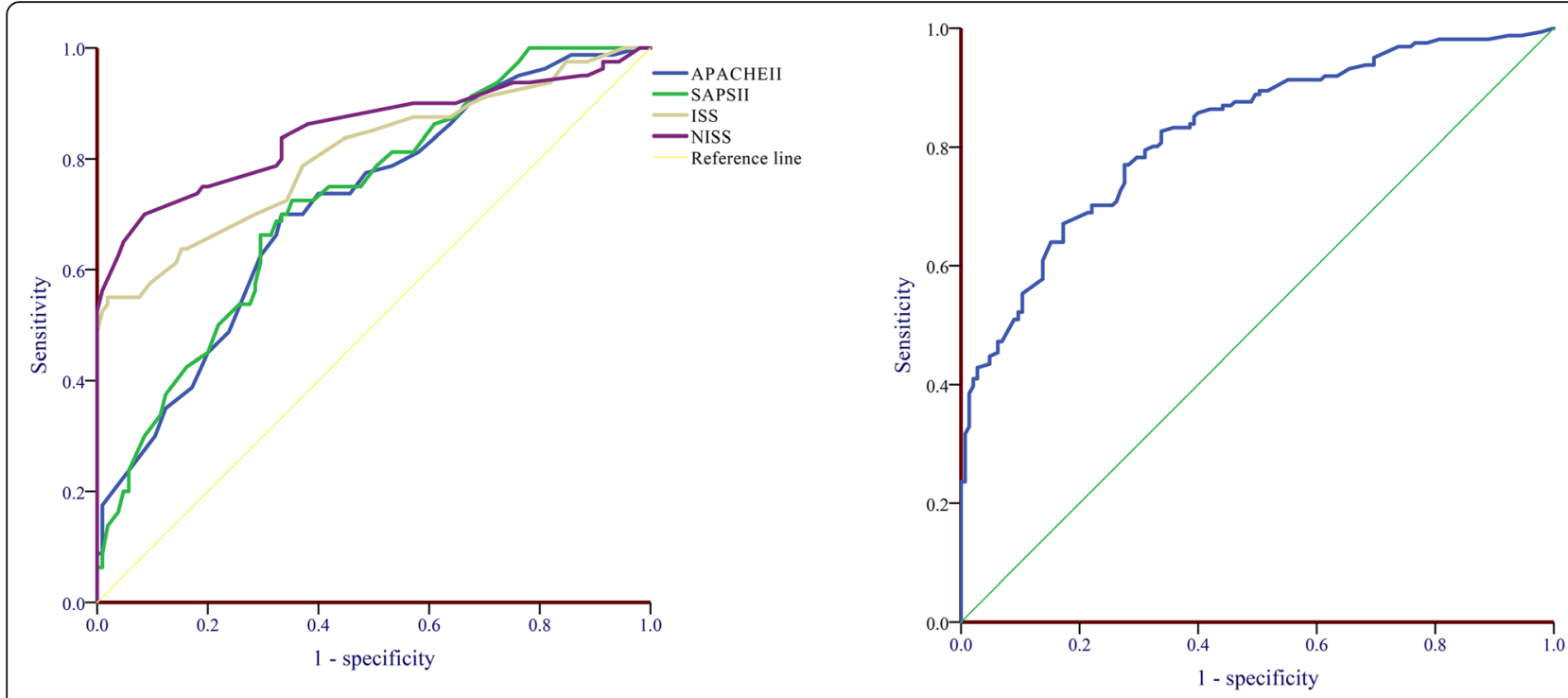

Fig. 3 The AUC of ISS, NISS, APACHE II, SPAS II, and TRISS in predicting in-hospital mortality among geriatric trauma patients. ISS, injury severity score; NISS, new injury severity score; SPAS II, simplified acute physiology score II; APACHE II, Acute Physiology and Chronic Health Evaluation II; TRISS, Trauma and Injury Severity Score

However, there is no study comparing the performance differences between the APACHE II versus SAPS II in predicting death among geriatric trauma patients. Our study tested the performance of the ISS, NISS, TRISS, APACHE II, and SAPS II for the prediction of inhospital mortality in geriatric trauma patients. The results suggested that the ISS, NISS, and TRISS might be superior to the APACHE II and SAPS II.

Some limitations of this study should be acknowledged. Firstly, only the annual reports of two large trauma databases were analyzed to describe the age profile of trauma patients, which may limit the generalization of the results. Then, the geriatric specific scoring system, known as the Geriatric Trauma Outcome Score (GTOS), was not evaluated in the present study $[39,40]$. However, it has been reported that there was no significant performance difference between the GTOS and other general injury severity measures $[12,13]$. Finally, it has the inherent limitations

Table 4 The matrix of AUC comparison between different scoring tool using $P$ value

\begin{tabular}{llllll}
\hline & SPAS II & APACHE II & ISS & NISS & TRISS \\
\hline SPAS II & & 0.61 & 0.07 & $<0.01$ & $<0.01$ \\
APACHE II & 0.61 & & 0.03 & $<0.01$ & $<0.01$ \\
ISS & 0.07 & 0.03 & & 0.02 & 0.34 \\
NISS & $<0.01$ & $<0.01$ & 0.02 & & 0.37 \\
TRISS & $<0.01$ & $<0.01$ & 0.34 & 0.37 & \\
\hline
\end{tabular}

SPAS II simplified acute physiology score II, APACHE II Acute Physiology and Chronic Health Evaluation II, ISS injury severity score, NISS new injury severity score, TRISS Trauma and Injury Severity Score, AUC area under the receiver operating characteristic curve of a secondary analysis, so conclusions should be considered only as hypothesis-generating.

\section{Conclusion}

The number and proportion of geriatric trauma patients are increasing rapidly. The ISS, NISS, and TRISS have better performance for the prediction of in-hospital mortality in geriatric trauma patients in comparison with the APACHE II and SAPS II.

\section{Supplementary information}

Supplementary information accompanies this paper at https://doi.org/10 1186/s13017-020-00340-1.

Additional file 1. List of different scoring too

\section{Abbreviations}

GCS: Glasgow score; Los: Length of stay; ICU: Intensive care unit; MV: Mechanical ventilation; SPAS II: Simplified acute physiology score II: APACHE II: Acute Physiology and Chronic Health Evaluation II; ISS: Injury severity score; NISS: New injury severity score; TRISS: Trauma and Injury Severity Score; AUC: Area under the receiver operating characteristic curve; RTS: Revised trauma score; NTDB: National trauma databank; ASCOT: A Severity Characterization of Trauma; MTOS: Major Trauma Outcome Study; GTOS: Geriatric Trauma Outcome Score

Acknowledgements

We acknowledged Lorenz et al. provide their data for this study.

\section{Authors' contributions}

LBJ and MZ contributed to the design of the study, the acquisition of data, the analysis, and interpretation. LBJ and ZJZ conducted the statistical analysis of the data. LBJ and ZJZ drafted the manuscript. All authors read and approved the final manuscript. 


\section{Funding}

This study was supported by Natural science foundation of Zhejiang Province (LQ2OH150006)

\section{Availability of data and materials}

The datasets used and analyzed during the current study are available from the corresponding author on reasonable request.

\section{Ethics approval and consent to participate}

This study was approved by the Institutional Review Board of the Second Affiliated Hospital, School of Medicine, Zhejiang University Research Ethics Committee, and the need for informed consent was waived (I2020001709).

\section{Consent for publication}

Not applicable.

\section{Competing interests}

We declare no competing interests.

Received: 1 August 2020 Accepted: 7 October 2020

Published online: 19 October 2020

\section{References}

1. Jiang $L, M a Y$, Jiang $S$, Ye $L$, Zheng $Z, X u Y$, Zhang M. Comparison of wholebody computed tomography vs selective radiological imaging on outcomes in major trauma patients: a meta-analysis. Scand J Trauma Resusc Emerg Med. 2014;22:54.

2. Moore L, Champion H, Tardif PA, Kuimi BL, O'Reilly G, Leppaniemi A, Cameron P, Palmer CS, Abu-Zidan FM, Gabbe B, et al. Impact of trauma system structure on injury outcomes: a systematic review and meta-analysis. World J Surg. 2018;42(5):1327-39.

3. Adams SD, Holcomb JB. Geriatric trauma. Curr Opin Crit Care. 2015;21(6): 520-6.

4. Benoit E, Stephen AH, Monaghan SF, Lueckel SN, Adams CA Jr. Geriatric Trauma. Rhode Island Med J. 2019;102(8):19-22.

5. Horst MA, Morgan ME, Vernon TM, Bradburn EH, Cook AD, Shtayyeh T, D'Andrea L, Rogers FB. The geriatric trauma patient: a neglected individual in a mature trauma system. J Trauma Acute Care Surg. 2020;89(1):192-8.

6. Southern AP, Lopez RA, Jwayyed S. Geriatric Trauma. In: StatPearls. Treasure Island: StatPearls Publishing; 2020

7. Callaway DW, Wolfe R. Geriatric trauma. Emergency medicine clinics of North America. 2007;25(3):837-60 x.

8. Pohlemann T, Histing T. Challenges in geriatric trauma care. Innovative surgical sciences. 2016:1(2):47-8.

9. Friess T, Hartwig E, Liener U, Sturm J, Hoffmann R. Geriatric trauma centers from the idea to implementation. What has been achieved? Der Unfallchirurg. 2016;119(1):7-11.

10. Gogol M, van den Heuvel D, Luttje D, Pullen R, Reingraber AC, Schulz RJ, Veer A, Wittrich A. Geriatric trauma centers - requirements catalog. An initiative to promote and guarantee the quality of care of elderly trauma patients receiving inpatient care. Z Gerontol Geriatr. 2014;47(4):310-6.

11. Pape HC, Friess T, Liener U, Ruchholtz S, Schmucker U, Sturm JA, Buecking G, Riem S, Hartwig E. Development of geriatric trauma centers-an effort by the German Society for Trauma and Orthopaedics. Injury. 2014;45(10):1513-5.

12. Barea-Mendoza JA, Chico-Fernandez M, Sanchez-Casado M, Molina-Diaz I, Quintana-Diaz M, Jimenez-Moragas JM, Perez-Barcena J, Llompart-Pou JA, en representacion del Grupo de Trabajo de Neurointensivismo y Trauma de la Sociedad Espanola de Medicina Intensiva CyUC. Predicting survival in geriatric trauma patients: a comparison between the TRISS methodology and the Geriatric Trauma Outcome Score. Cirugia Espanola. 2018;96(6):357-62.

13. Madni TD, Ekeh AP, Brakenridge SC, Brasel KJ, Joseph B, Inaba K, Bruns BR, Kerby JD, Cuschieri J, Mohler MJ, et al. A comparison of prognosis calculators for geriatric trauma: a prognostic assessment of life and limitations after trauma in the elderly consortium study. J Trauma Acute Care Surg. 2017:83(1):90-6

14. Cook AC, Joseph B, Mohler MJ, Inaba K, Bruns BR, Nakonezny PA, Kerby JD, Brasel KJ, Wolf SE, Cuschieri J, et al. Validation of a geriatric trauma prognosis calculator: a P.A.L.Li.A.T.E. consortium study. J Am Geriatr Soc. 2017;65(10):2302-7.

15. Mehmood A, Hung YW, He H, Ali S, Bachani AM. Performance of injury severity measures in trauma research: a literature review and validation analysis of studies from low-income and middle-income countries. BMJ Open. 2019;9(1):e023161.

16. Peterer L, Ossendorf C, Jensen KO, Osterhoff G, Mica L, Seifert B, Werner CML, Simmen HP, Pape HC, Sprengel K. Implementation of new standard operating procedures for geriatric trauma patients with multiple injuries: a single level I trauma centre study. BMC Geriatr. 2019;19(1):359.

17. Peterer L, Ossendorf C, Jensen KO, Osterhoff G, Mica L, Seifert B, Werner CML, Simmen HP, Pape HC, Sprengel K. Implementation of new standard operating procedures for geriatric trauma patients with multiple injuries: a single level I trauma centre study, v5, Dryad. Dataset. 2020. https://doi.org/ 10.5061/dryad.2v6wwpzhk.

18. Watts G. Jiang Baoguo: one, two, three against trauma in China. Lancet. 2017:390(10104):1729

19. Ludi E, Boeck M, South S, Monasterio J, Swaroop M, Foianini E. Geriatric trauma in Santa Cruz, Bolivia. The Journal of surgical research. 2019;244:212-7.

20. Gioffre-Florio M, Murabito LM, Visalli C, Pergolizzi FP, Fama F. Trauma in elderly patients: a study of prevalence, comorbidities and gender differences. I/ Giornale di chirurgia. 2018;39(1):35-40.

21. Kehoe A, Smith JE, Edwards A, Yates D, Lecky F. The changing face of major trauma in the UK. EMJ. 2015;32(12):911-5.

22. Cutugno CL. The 'graying' of trauma care: addressing traumatic injury in older adults. Am J Nurs. 2011;111(11):40-8 quiz 49-50.

23. Bortz KL. Creating a geriatric-focused model of care in trauma with geriatric education. J Trauma Nurs. 2015;22(6):301-5 quiz E301-302.

24. Moran CG, Lecky F, Bouamra O, Lawrence T, Edwards A, Woodford M, Willett K, Coats TJ. Changing the system - major trauma patients and their outcomes in the NHS (England) 2008-17. EClinicalMedicine. 2018;2-3:13-21.

25. Doyle R, Brent L, Connolly A, Breslin T, Jones S, Kelly F, Lawrence T, Deasy C. Major trauma in the older person - major challenges ahead. Age Ageing. 2019:48(Supplement_3):iii1-iii16.

26. Baker SP, O'Neill B, Haddon W Jr, Long WB. The injury severity score: a method for describing patients with multiple injuries and evaluating emergency care. J Trauma. 1974;14(3):187-96.

27. Frankema SP, Steyerberg EW, Edwards MJ, van Vugt AB. Comparison of current injury scales for survival chance estimation: an evaluation comparing the predictive performance of the ISS, NISS, and AP scores in a Dutch local trauma registration. J Trauma. 2005;58(3):596-604.

28. Lavoie A, Moore L, LeSage N, Liberman M, Sampalis JS. The new injury severity score: a more accurate predictor of in-hospital mortality than the injury severity score. J Trauma. 2004;56(6):1312-20.

29. Nogueira Lde S, Domingues Cde A, Campos Mde A, Sousa RM. Ten years of new injury severity score (NISS): is it a possible change? Revista LatinoAmericana de Enfermagem. 2008;16(2):314-9.

30. Boyd CR, Tolson MA, Copes WS. Evaluating trauma care: the TRISS method. Trauma Score and the Injury Severity Score. J Trauma. 1987;27(4):370-8.

31. Javali RH, Krishnamoorthy PA, Srinivasarangan M, Suraj S. Comparison of Injury Severity Score, New Injury Severity Score, Revised Trauma Score and Trauma and Injury Severity Score for Mortality Prediction in Elderly Trauma Patients. Ind J Crit Care Med. 2019:23(2):73-7.

32. Yousefzadeh-Chabok S, Hosseinpour M, Kouchakinejad-Eramsadati L, Ranjbar F, Malekpouri R, Razzaghi A, Mohtasham-Amiri Z. Comparison of revised trauma score, injury severity score and trauma and injury severity score for mortality prediction in elderly trauma patients. Ulusal travma ve acil cerrahi dergisi. 2016;22(6):536-40.

33. Thanapaisal C, Saksaen P. A comparison of the Acute Physiology and Chronic Health Evaluation (APACHE) II score and the Trauma-Injury Severity Score (TRISS) for outcome assessment in Srinagarind Intensive Care Unit trauma patients. J Med Assoc Thailand. 2012;95(Suppl 11):S25-33.

34. Hwang SY, Lee JH, Lee YH, Hong CK, Sung AJ, Choi YC. Comparison of the sequential organ failure assessment, acute physiology and chronic health evaluation ii scoring system, and trauma and injury severity score method for predicting the outcomes of intensive care unit trauma patients. Am J Emerg Med. 2012;30(5):749-53.

35. Vassar MJ, Lewis FR Jr, Chambers JA, Mullins RJ, O'Brien PE, Weigelt JA, Hoang MT, Holcroft JW. Prediction of outcome in intensive care unit trauma patients: a multicenter study of Acute Physiology and Chronic Health Evaluation (APACHE), Trauma and Injury Severity Score (TRISS), and a 24-hour intensive care unit (ICU) point system. J Trauma. 1999; 47(2):324-9.

36. Wong DT, Barrow PM, Gomez M, McGuire GP. A comparison of the Acute Physiology and Chronic Health Evaluation (APACHE) II score and the 
Trauma-Injury Severity Score (TRISS) for outcome assessment in intensive care unit trauma patients. Crit Care Med. 1996;24(10):1642-8.

37. Reiter A, Mauritz W, Jordan B, Lang T, Pölzl A, Pelinka L, Metnitz PG. Improving risk adjustment in critically ill trauma patients: the TRISS-SAPS Score. J Trauma. 2004;57(2):375-80,

38. Fueglistaler P, Amsler F, Schüepp M, Fueglistaler-Montali I, Attenberger C, Pargger H, Jacob AL, Gross T. Prognostic value of Sequential Organ Failure Assessment and Simplified Acute Physiology II Score compared with trauma scores in the outcome of multiple-trauma patients. Am J Surg. 2010;200(2):204-14.

39. Zhao FZ, Wolf SE, Nakonezny PA, Minhajuddin A, Rhodes RL, Paulk ME, Phelan HA. Estimating Geriatric Mortality after Injury Using Age, Injury Severity, and Performance of a Transfusion: The Geriatric Trauma Outcome Score. J Palliat Med. 2015;18(8):677-81.

40. Cook AC, Joseph B, Inaba K, Nakonezny PA, Bruns BR, Kerby JD, Brasel KJ, Wolf SE, Cuschieri J, Paulk ME, et al. Multicenter external validation of the geriatric trauma outcome score: a study by the prognostic assessment of life and limitations after trauma in the elderly (PALLIATE) consortium. J Trauma Acute Care Surg. 2016;80(2):204-9.

\section{Publisher's Note}

Springer Nature remains neutral with regard to jurisdictional claims in published maps and institutional affiliations.

Ready to submit your research? Choose BMC and benefit from:

- fast, convenient online submission

- thorough peer review by experienced researchers in your field

- rapid publication on acceptance

- support for research data, including large and complex data types

- gold Open Access which fosters wider collaboration and increased citations

- maximum visibility for your research: over $100 \mathrm{M}$ website views per year

At $\mathrm{BMC}$, research is always in progress.

Learn more biomedcentral.com/submissions 